\title{
Voluntary drinking and hydration in trained, heat-acclimatized girls exercising in a hot and humid climate
}

\author{
Anita M. Rivera-Brown • Farah A. Ramírez-Marrero • \\ Boguslaw Wilk • Oded Bar-Or
}

Published online: 15 May 2008

(C) Springer-Verlag 2008

\section{Erratum to: Eur J Appl Physiol (2008) 103:109-116 DOI 10.1007/s00421-008-0682-1}

Lines 18-22 of Abstract: The average amount of urine produced $(W=269.8 \pm 85.9 ; \mathrm{FW}=320.8 \pm 87.2 ; \mathrm{CNa}=$ $85.6 \pm 9.3 \mathrm{~g}$ ) was 73 and $68 \%$ higher during $\mathrm{FW}$ and $W$, respectively, compared to $\mathrm{CNa}(\mathrm{CNa}$ vs $\mathrm{FW}, P<0.05)$.
Should read: The average amount of urine produced $(W=269.8 \pm 85.9 ; \mathrm{FW}=320.8 \pm 87.2 ; \mathrm{CNa}=85.6 \pm 9.3 \mathrm{~g})$ was 73 and $68 \%$ lower during $\mathrm{CNa}$ compared to $\mathrm{FW}$ and $W$, respectively ( $\mathrm{CNa}$ vs $\mathrm{FW}, P<0.05, \mathrm{CNa}$ vs $W$, $P=0.06)$.

The online version of the original article can be found under doi:10.1007/s00421-008-0682-1.

\footnotetext{
A. M. Rivera-Brown ( $\square)$

Center for Sports Health and Exercise Sciences at the Albergue

Olímpico, Department of Physical Medicine,

Rehabilitation and Sports Medicine,

University of Puerto Rico School of Medicine,

P.O. Box 2004, Salinas 00751, Puerto Rico

e-mail: aniriver@coqui.net
}

\section{F. A. Ramírez-Marrero}

Department of Physical Education and Recreation,

University of Puerto Rico, San Juan, Puerto Rico

B. Wilk $\cdot$ O. Bar-Or

Children's Exercise and Nutrition Centre,

McMaster University, Hamilton, ON, Canada 